\title{
HIGH-PRECISION SATELLITE LEVELING AND INVESTIGATION OF THE LOCAL GEOID MODEL IN THE TERRITORY OF KASHKADARYA REGION
}

\author{
Fazilova D.Sh. ${ }^{1}$ \\ ${ }^{1}$ Doctor of Physical and Mathematical Sciences, Head of the Space researches laboratory at the \\ Astronomical Institute of the Uzbekistan Academy of Sciences Uzbekistan, Tashkent,
}

\begin{abstract}
Magdiev H.N. ${ }^{2}$
${ }^{2}$ Head of project implementation unit at the Agency for cadaster of the Republic of Uzbekistan; junior researcher at the Astronomical Institute of the Uzbekistan Academy of Sciences

Uzbekistan, Tashkent,

\author{
Halimov B.T. ${ }^{3}$ \\ ${ }^{3}$ Junior researcher at the Astronomical Institute of the Uzbekistan Academy of Sciences \\ Uzbekistan, Tashkent,
}

"Corresponding author: Dilbarkhon Fazilova

Article DOI: https://doi.org/10.36713/epra5788

\begin{abstract}
In this paper, a study of the accuracy of obtaining normal heights using Global Geopotential Models EGM2008, EIGEN6C4, GECO and GNSS measurements for the territory of the Kashkadarya region in Uzbekistan is carried out. The heights obtained by the classical leveling in Baltic reference system were used as reference data. EIGEN-6C4 and GECO models were recommended for definition a preliminary quasi - geoid model of the region.
\end{abstract}

KEYWORDS: GNSS and classical leveling, Global Geopotential Model, height anomaly

\section{INTRODUCTION}

The Baltic height system was adopted in 1977 (BK77) and is in use up to nowadays in Uzbekistan. The reference point of the BK77 is the zero-mark of the Kronstadt tide gauge in Pulkovo. The normal heights in the system obtained using classical leveling methods are calculated relative to the quasigeoid. The satellite geodesy methods such as Global Navigation Satellite Systems (GNSS) are widely used in different countries for height system construction on base GNSS-leveling, especially for difficult to access for observation and with high mountainous relief areas [1, 2]. With significant improvements in positioning technology, now enabling centimeterlevel positioning capability GNSS geodetic network built in Uzbekistan [3]. While the horizontal coordinates of the network will use directly in engineering applications, the vertical component (ellipsoidal height) will convert to normal heights beforehand. The precisely determined height anomaly $(\xi)$ is necessary for the transformation from GNSS-derived ellipsoidal height (h) to normal height (H) [4]:

$$
H=h-\xi
$$

(1)

The height system's reference surface quasi-geoid serves as complementary geophysical information for the research of Earth's mass density anomaly structure, interpretation of the stress fields, tectonic forces, and other applications [5]. Unfortunately, there is no systematic database of the quasi-geoid for 
normal heights definition on the territory of the country.

Recently, the highest degrees (up to 2190) Global Geopotential Models (GGM) provide major advance for numerous geodetic uses. These include the model of the National Geospatial-Intelligence Agency of the US Department of Defense (NGA) EGM2008 solution, as well as models of the International Center for Global Earth Models (ICGEM) EIGEN-6C4 and GECO [6, 7, 8]. However, the accuracy of the models varies depend from the availability of data for different regions [9]. The RMS value errors of the height anomalies for territories with ground-based measurements is about $11 \mathrm{~cm}$, while for Central Asia the accuracy of these values are $35 \mathrm{~cm}$. Moreover, mountain areas are the most poorly studied [10]. The purpose of this study is to compare the values of normal heights calculated from the data of the high resolution models EGM2008, EIGEN-6C4, GECO, and GNSS measurements at the geodetic points in Kashkadarya region in the Republic Uzbekistan with the values of normal heights in BK77 system.

\section{DATA AND METHOD}

Kashkadsarya region is located in the southern part of Uzbekistan in the Kashkadarya river basin and covers of about $28570 \mathrm{~km}^{2}$. Pamir Alay mountain system extends to the eastern part of the region. It is one of the most seismically active regions of the country characterized by a complex geological structure, high modern mobility of the
Earth's crust. The region has developed such industries as the extraction of hydrocarbons (oil, gas, and condensate) and the processing of natural gas.

Data used for the study include:

(1) GNSS network stations distributed over the whole region (Figure 1). In total 24 stations were installed from 2005 to 2015 for the survey applications. GNSS measurements were processed with GAMIT/GLOBK ver. 10.7 software for relative positioning [11]. GAMIT solutions were combined using a Kalman filter estimator in the GLOBK software package to estimate a consistent set of positions in the International Terrestrial Reference Frame ITRF2014 [12].

(2) The classic leveling data in BK77 referenced to Krasovsky ellipsoid downloaded from free available database of the International Gravimetric Bureau in Toulouse [13].

(3) The GGM used in this study are summarized in Table 1. The first high resolution model EGM08 was computed from a global set of area-mean free-air gravity anomalies integrated with the information of the GRACE gravity mission [6]. EIGEN-6C4 model was developed using as both GOCE, Lageos satellite data and terrestrial gravity measurements [7]. GECO model is combination a GOCE satellite-only and EGM08 global models for improving the accuracy in areas where no data were available at the time of EGM08 computation [8].

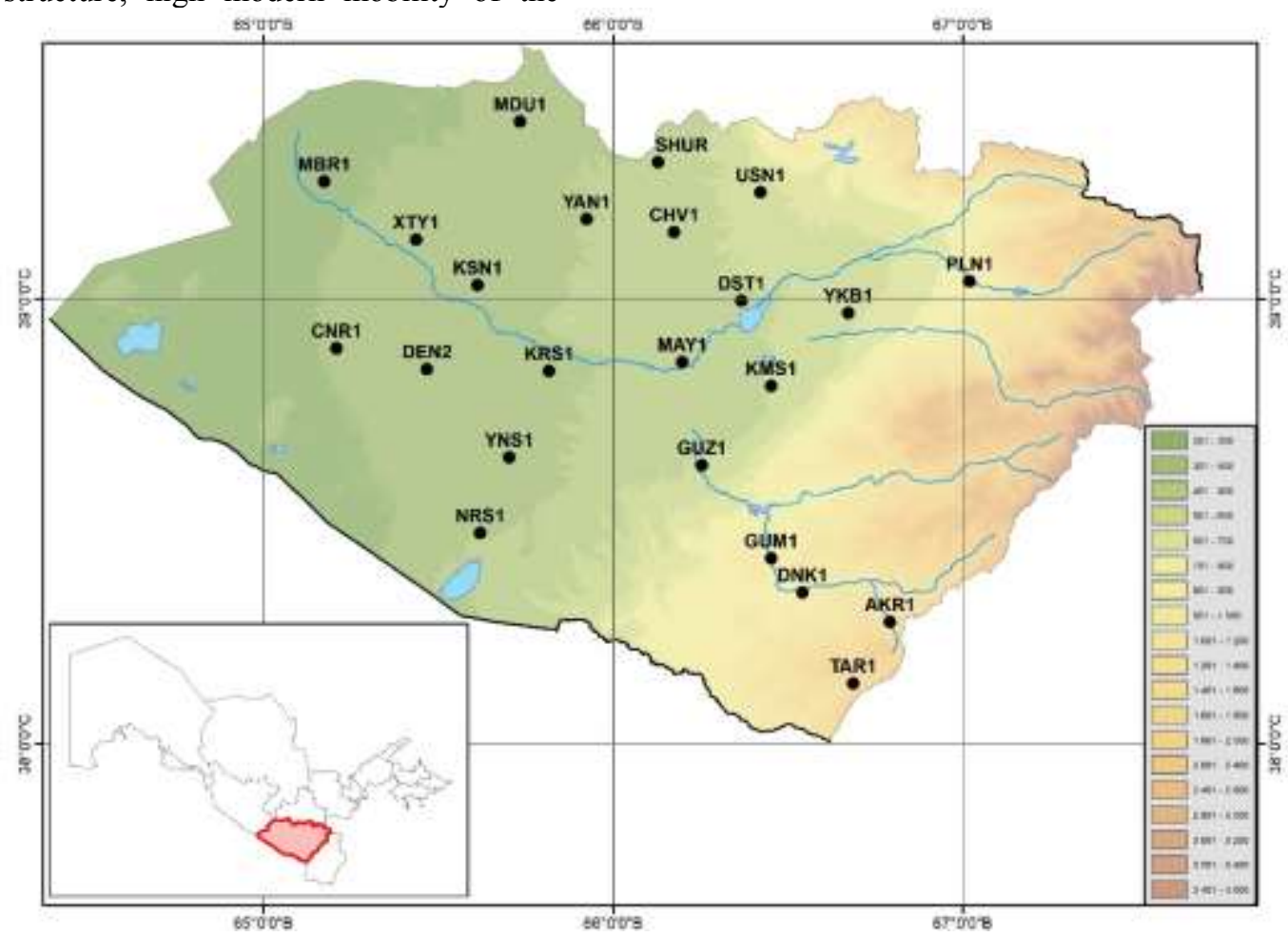

Figure 1: Study area and distribution of GNSS network 
Volume: 8 | Issue: 4 | November 2020 | Journal DOI : 10.36713/epra0713 | SJIF Impact Factor (2020): 8.007

Table 1: Data used for GGM

\begin{tabular}{|c|c|c|c|}
\hline GGM & $\begin{array}{c}\text { Time of } \\
\text { releasing }\end{array}$ & $\begin{array}{c}\text { Max } \\
\text { degree/order }\end{array}$ & Data used for GGM \\
\hline EGM2008 & 2008 & 2190 & S(GRACE), G, A \\
\hline EIGEN-6C4 & 2014 & 2190 & S(GOCE, GRACE, LAGEOS), G, A \\
\hline GECO & 2015 & 2190 & EGM2008, S(GOCE) \\
\hline
\end{tabular}

*Data description: S: satellite, G- terrestrial gravimetric measurements, A -altimetry.

Height anomalies for three GGMs at control points are received using Calculation Service of the ICGEM [14]. The service allows calculating height anomalies above WGS-84 ellipsoid for the global model with a $1^{\circ} \times 1^{\circ}$ grid using equation:

$$
\xi(\lambda, \varphi)=\frac{G M}{r \gamma(r, \varphi)} \sum_{l=2}^{l_{\max }}\left(\frac{R}{r}\right)^{l} \sum_{m=0}^{l} P_{l m}(\sin \varphi)\left(\bar{C}_{l m} \cos m \lambda+\bar{S}_{l m} \sin m \lambda\right)
$$

where $G M$ - a product of gravitational constant and the Earth's mass, $Y$ - normal gravity on the surface of the reference ellipsoid, $(r, \varphi, \lambda)$ - spherical geocentric coordinates of computation point, $R$ - mean radius of the Earth, $\bar{P}_{l m}$ - fully normalized Legendre function of degree $l$ and order $m, l_{\max }$ is the maximum degree of the spherical expansion, $\bar{C}_{l m}, \bar{S}_{l m}$ are the spherical harmonic coefficients of the disturbing potential.

The normal height $H_{G G M}$ was calculated from GGMs height anomaly ( $\xi$ ) and GNSS-derived ellipsoidal height $h$ using formula (1). Comparative evaluation of the normal heights was carried out by the residuals $\Delta H(P)$ between the estimated $H_{G G M}$ and measured by classic methods $H_{\text {Classic }}$ normal heights at each control point $\mathrm{P}$

$$
\Delta H(P)=H_{G G M}(P)-H_{\text {Classic }}(P)
$$

For residuals, maximum, minimum, mean error (ME) and the root means square error (RMSE) were calculated. The RMSE characterizes the difference between the modeled values $\mathrm{H}_{\mathrm{GGM}}$ and the reference ones ( $\mathrm{H}_{\text {Classic }}$ in our case) and $\mathrm{ME}$ gives an estimate of the offset from the reference. The equations as follows [15]:

$$
\begin{gathered}
M E=\frac{1}{n} \sum_{i=1}^{n}\left(H_{G G M}-H_{\text {Classic }}\right) \\
R M S E=\sqrt{\frac{1}{n} \sum_{i=1}^{n}\left(H_{G G M}-H_{\text {Classic }}\right)^{2}}
\end{gathered}
$$

"Natural Neighbor" interpolation method was used in the ArcGIS software package for creation of a continuous surface of normal heights over the area [16].

\section{RESULTS}

The difference $\Delta H(P)$ between estimated and reference values of the normal heights ranged from $-10.96 \mathrm{~cm}$ to $29.92 \mathrm{~cm}$, from $-4.22 \mathrm{~cm}$ to 15.38 $\mathrm{cm}$, from $-12.82 \mathrm{~cm}$ to $15.88 \mathrm{~cm}$ respectively for EGM2008, EIGEN-6C4, and GECO (Table 2). The values of the calculated differences showed that for all models the errors are within 3 sigma (or RMSE) and confirmed as both high quality of the GGMs and the possibility of applying each of them for practical purposes in the region. We have also confirmed that the EIGEN-6C4 and GECO models "correct" EGM2008 for regionswith poorly terrestrial data distribution [7, 8]. The RMSE for the EIGEN-6C4 and GECO RMSE are comparatively higher than the EGM2008. However, it should be noted that although the offset parameter (ME) for EIGEN-6C4 and GECO models is almost the same, the EIGEN-6C4 produced the lowest RMSE of $5.99 \mathrm{~cm}$.

Table 2. The statistics of the calculated normal heights difference $\Delta H(P)$

\begin{tabular}{|c|c|c|c|c|c|}
\hline & Min, cm & Max, cm & Mean, cm & ME, cm & RMSE, cm \\
\hline EGM2008 & -10.96 & 29.92 & 11.80 & 11.80 & 15.38 \\
\hline EIGEN-6C4 & -4.22 & 15.38 & 2.75 & 2.75 & 5.99 \\
\hline GEC0 & -12.82 & 15.88 & 2.73 & 2.73 & 8.55 \\
\hline
\end{tabular}

The homogeneous surfaces obtained by the Natural Neighbor method for each difference (GGM - Classic) residuals are shown in Figure $2(\mathrm{a}-\mathrm{c})$. The map of residuals shows the following prominent features: the residuals of differences for the northern flat part of the region (especially near the YAN1, CHV1, DEN2 stations) show almost the same result. However, for the eastern part of the region near the Pamir Alay mountain system for all models, we can observe different solutions. The results obtained by 
EPRA International Journal of Economic Growth and Environmental Issues- Peer Reviewed Journal

ISSN: 2321-6247

Volume: 8 | Issue: 4 | November 2020 | Journal DOI : 10.36713/epra0713 | SJIF Impact Factor (2020): 8.007

the EIGEN-6C4 model are represented by a continuous homogeneous surface. A comparison with the surface obtained by the reference EGM2008 model shows that the results of the GECO model more reliably represent the mountainous part of the territory.

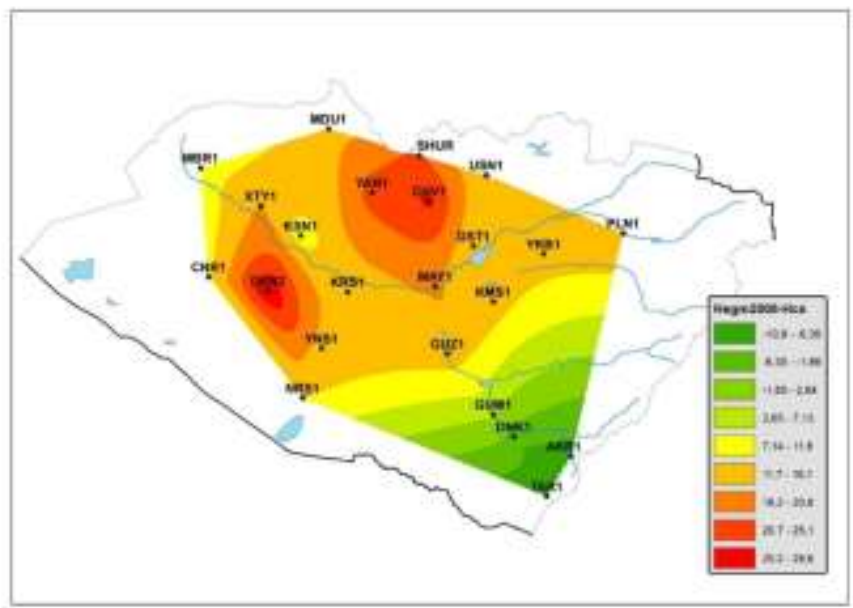

a)

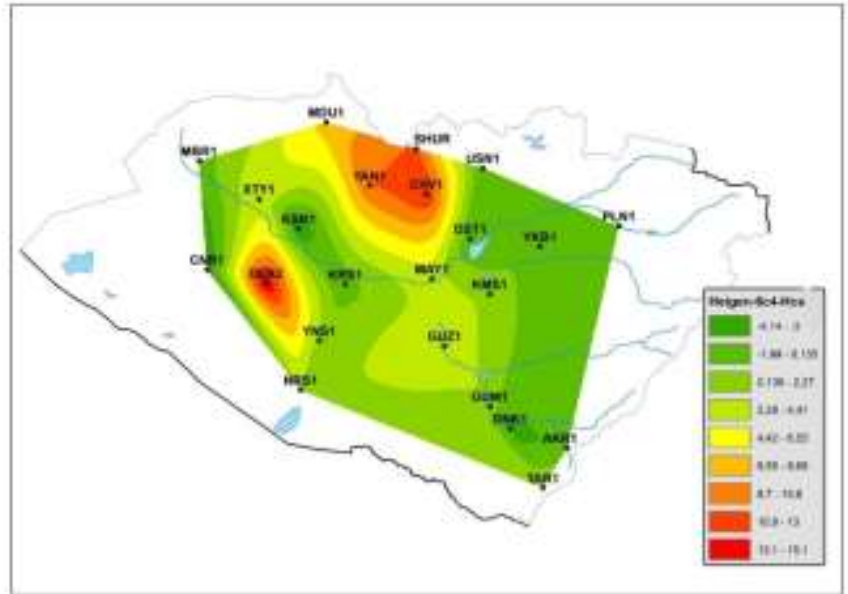

b)

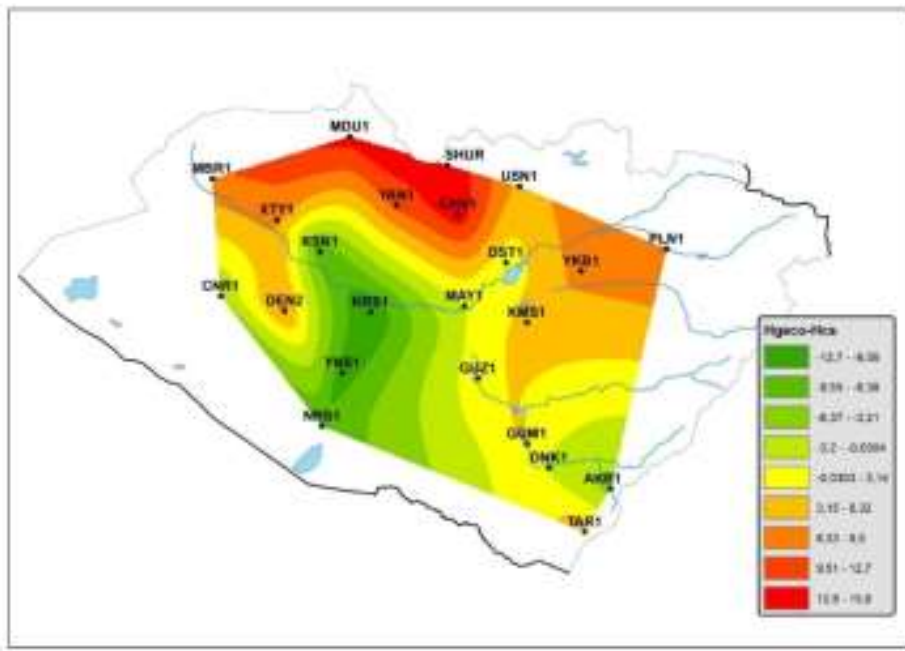

c)

Figure 2: Difference between GGM-derived and classical leveling normal heights distribution: (a) EGM2008, (b) EIGEN-6C4, (c) GECO 


\section{CONCLUSIONS}

The present study is preliminary work for assessment of the high resolution Global Geopotential Models EGM2008, EIGEN-6C4, and GECO over the Kashkadarya. Classical leveling data in Baltic normal height system were used as a reference. The statistical analysis and RMSE values confirmed the good correlation between the GGMderived normal heights with the classical ones. The results indicate that EIGEN-6C4 and GECO based regional models may possess great potential in providing further works in the quasi-geoid model determination for survey applications.

\section{Acknowledgments.}

This work was carried out within the scientific and applied project FA-A5-F014 of the Astronomical Institute of Uzbekistan with the financial support of the Ministry of Innovative Development of the Republic of Uzbekistan. We are very grateful to the National Center of Geodesy and Cartography, who organized the GNSS experiment and made the data available to this study.

\section{REFERENCES}

1. Featherstone W.E., Denith M.S., Kirby, J.F. Strategies for the accurate determination of Orthometric Heights. Surv. Rev. 1998, 34 (267): 278-296.

2. Kenyeres A. GPS/Leveling. In: Grafarend E. (eds) Encyclopedia of Geodesy. Springer, Cham. 2016

3. Fazilova D. The review and development of a modern GNSS network and datum in Uzbekistan. Geodesy and Geodynamics. 2017, 8(3): 187-192. https://doi.org/10.1016/j.geog.2017.02.006

4. Heiskanen W.A., Moritz H. Physical Geodesy (W.H. Freeman and Company San Francisco). 1967: 370.

5. Vanicek P., Christou N.T. Geoid and its Geophysical Interpretations. CRC Press, Inc., Boca Raton, Ann Arbor, London. 1994.

6. Pavlis N., Holmes S., Kenyon S., Factor J. The development and evaluation of the Earth Gravitional Model 2008 (EGM08), Journal of Geophysical research. 2012, 117(B4): $\quad$ 1-38. https://doi.org/10.1029/2011jB008916

7. Förste Ch., Bruinsma S. L., Abrikosov O., Lemoine J.-M., Marty J.- Ch., Flechtner F., Balmino G., Barthelmes $F$., Biancale $R$. EIGEN-6C4 The latest combined global gravity field model including GOCE data up to degree and order 2190 of GFZ Potsdam and GRGS Toulouse. GFZ Data Services. 2014. doi.org/10.5880/icgem.2015.1

8. Gilardoni M., Reguzzoni M., Sampietro D. GECO: a global gravity model by locally combing GOCE data and EGM08. Studia Geophysica et Geodetica. 2016, $60(2)$ : 228 247.https://doi.org/10.1007/s11200-015-

1114-4

9. Newton's bulletin. External Quality Evaluation Reports of EGM08 Issue. 2009 (4). $\quad$ http:///bgi.omp.obsmip.fr/publications/newton_bulletin

10. Nepoklonov V.B. On the use of new models of the gravitational field of the Earth in automated survey and design technologies. Automated survey and design technologies. 2009, 3. In Russian. http://www.credodialogue.com/journal.aspx

11. Herring T.A., King R.W., Floyd M., McClusky S.C. Introduction to GAMIT/GLOBK. Release 10.6. Technical report. Massachussetts Institute of Tectonology. 2015

12. Altamimi Z., Rebischung P., Métivier L., Collilieux X. ITRF2014: a new release of the international terrestrial reference frame modeling nonlinear station motions. $J$. Geophys. Res., Solid Earth. 2016, 121 (8): 6109-6131.

13. Drewes H., Kuglitsch F., Adam J., Rozsa S. The International Gravimetric Bureau. Journal of Geodesy. 2016, .90 (10): 11861190.

14. Barthelmes F., Köhler W. International Centre for Global Earth Models (ICGEM), in: Drewes, H., Kuglitsch, F., Adám, J. et.al, The Geodesists Handbook. Journal of Geodesy. 2016, 90 (10): 907-1205.

15. Mukherjee S., Joshi P., Mukherjee S., Ghosh A., Garg R., Mukhopadhya, A. Evaluation of vertical accuracy of open source Digital Elevation Model (DEM). International Journal of Applied Earth Observation and Geoinformation. 2013, 21:205-217. doi: 10.1016/j.jag.2012.09.004.

16. Fazilova D., Magdiev H. Comparative study of interpolation methods in development of local geoid. International Journal of Geoinformatics. 2018, 14(1): 29-33. 